and Company, Fresenius, Galapagos, Gilead, GlaxoSmithKline, Janssen, Nordic Pharma, Pfizer Roche, and UCB, Salome Kristensen: None declared DOI: 10.1136/annrheumdis-2020-eular.523

\section{AB1256 CORRELATION BETWEEN SERUM CALPROTECTIN LEVELS, RAPID3 AND DISEASE ACTIVITY MEASURES IN PATIENTS WITH RHEUMATOID ARTHRITIS}

M. Valls Roc ${ }^{1}$, O. Codina Guinó ${ }^{1}$, M. Sala Gomez ${ }^{1}$, S. Castell Quiñones ${ }^{1}$, C. Mora Maruny ${ }^{2} .{ }^{1}$ Hospital de Figueres, Rheumatology, Figueres, Spain; ${ }^{2}$ Hospital de Figueres, Clinical Analysis Department, Figueres, Spain

Background: Tight control of rheumatoid arthritis (RA) is essential and we need a validated, objective and reproducible disease measure to achieve it. There is not gold standard in RA. There is a rising interest in evaluating disease activity on the patient's point of view using patient-reported outcomes like RAPID3. Furthermore, some new biomarkers have appeared, like serum calprotectin, with promising results on its analyzing.

Objectives: To evaluate correlation between disease activity measures usually used in patients with RA (DAS28 ESR/CRP, SDAI and CDAI) and other alternative tools (RAPID3 and calprotectin). To analyze correlation between RAPID3 and serum calprotectin levels.

Methods: A cross-sectional study was performed. RA-patients $(n=114)$ according to the ACR/EULAR 2010 classification criteria were consecutively enrolled from Rheumatology department at Hospital de Figueres during the period from February to June 2019. Disease activity, biomarkers and the assessment of the patient's health status with RAPID3 data were collected. Modified RAPID3 (mRAPID3) was calculated by subtracting the questions about the mood included in the questionnaire ( $k, I, m$ questions) to the results of the RAPID3 as if it were a response of the HAQ test. Coefficient Spearman's correlation ( $r$ ) was used to assess the relationship between the variables, and coefficient of determination ( $r$-squared $=r^{2}$ and adjusted $r^{2}$ ) was used to show the strength of correlation.

Results: 114 patients were included: 71\% women, mean (SD) age 60(11) years, median disease duration $13(8)$ years. $80 \%$ had positive RF and $70 \%$ positive ACCP antibodies. $52 \%$ had erosions. $89 \%$ patients had been receiving treatment with csDMARDs, $38 \%$ with bDMARDs o dsDMARS and $66 \%$ with glucocorticoids. Disease activity measures' median values were DAS28ESR 3.07, DAS28CRP 2.76, SDAI 9.62 and CDAI 8.99 and showed low activity. The mean values of RAPID3 y mRAPID3 showed moderate activity (8.95 and 8.68 respectively). Median serum calprotectin level was $1.48 \mu \mathrm{g} / \mathrm{ml}$.

All correlations between variables were statistically significant and directly proportional although with different values (table).

Spearman's correlation coefficient between mRAPID3, serum calprotectin, disease activity scores and laboratory parameters

\begin{tabular}{lcccccccc}
\hline & mRAPID3 & Calprotectin & CRP & ESR & DAS28ESR & DAS28PCR SDAI CDAI \\
\hline mRAPID3 & 1 & & & & & & & \\
Calprotectin & 0.23 & 1 & & & & & & \\
CRP & 0.33 & 0.59 & 1 & & & & & \\
ESR & 0.23 & 0.39 & 0.54 & 1 & & & & \\
DAS28-ESR & 0.62 & 0.32 & 0.41 & 0.62 & 1 & & & \\
DAS28-CRP & 0.69 & 0.32 & 0.42 & 0.28 & 0.83 & 1 & 1 \\
SDAI & 0.74 & 0.31 & 0.35 & 0.27 & 0.82 & 0.91 & 1 \\
CDAI & 0.73 & 0.25 & 0.24 & 0.21 & 0.80 & 0.89 & 0.99 & 1 \\
\hline
\end{tabular}

DAS28: Disease Activity Score, SDAI: Simplified Disease Activity Index, CDAI: Clinical Disease Activity Index, RAPID3m: Routine Assessment of Patient Index Data 3 modificative with k,I,m questions. CRP: C-reactive protein. ESR: erythrocyte sedimentation rate

Coefficient of determination found a weak association between RAPID3 and mRAPID3 with DAS28ESR $\left(r^{2}=0,38\right)$ and moderate with DAS28CRP, SDAI and $\operatorname{CDAI}\left(r^{2}=0,47,0,55\right.$ y 0,53$)$. Determination serum calprotectin levels together with RAPID3 or mRAPID3 increased strength of correlation between DAS28ESR, DAS28CRP, SDAI and CDAl with RAPID3 (adjusted $r^{2}=0,40,0,49,0,56,0,52$ ) and with mRAPID3 (adjusted $r^{2}=0,41,0,50,0,56,0,53$ ). Correlation between RAPID3 and serum calprotectin levels was very weak $\left(r^{2}=0,05\right)$.

Conclusion: Correlation between disease activity measures and mRAPID3 was strong, but it was weak with serum calprotectin levels. Correlation strength between RAPID3 and DAS28ESR was low and it was moderate with other composite indices, it maintained with RAPID3m and improved by adding serum calprotectin levels although modestly. There was a very weak correlation between RAPID3 and serum calprotectin levels suggesting that these two variables give us different information about the disease activity.
Acknowledgments: Mrs. Dolors Ragolta. Mr. Carlos Sanchez Piedra and Mr. Fernando Sanchez Alonso

Disclosure of Interests: None declared

DOI: 10.1136/annrheumdis-2020-eular.1024

\section{\begin{tabular}{|l|l}
\hline AB1257 & SCREENING FOR IMMUNOGLOBULIN A ANTIBODY \\
\hline
\end{tabular} REACTIVITY IN EARLY AXIAL SPONDYLOARTHRITIS IDENTIFIES NOVEL ANTIGENIC TARGETS}

P. Vandormael ${ }^{1}$, D. Quaden ${ }^{1}$, P. Ruytinx ${ }^{1}$, J. Janssens ${ }^{1}$, J. Vanhoof ${ }^{2}$,

P. Geusens ${ }^{1,2,3}$, V. Somers ${ }^{1} .{ }^{1}$ Hasselt University, Biomedical Research Institute, Diepenbeek, Belgium; ${ }^{2}$ ReumaClinic, Genk, Belgium $;{ }^{3}$ Maastricht University

Medical Center, Internal Medicine, Rheumatology, Maastricht, Netherlands

Background: Although autoantibodies are not generally considered to be a hallmark of axial spondyloarthritis (axSpA), increasing evidence suggests the presence of autoantibodies in a subset of axSpA patients. Most of these described antibodies are of the immunoglobulin $\mathrm{G}(\mathrm{IgG})$ isotype while other antibody isotypes are less well studied. Antibodies of the IgA isotype can be of interest due to the strong link between gut inflammation and spondyloarthropathies.

Objectives: The aim of this study was to identify and characterize novel IgA isotype (auto)antibodies specific for early axSpA patients.

Methods: An axSpA cDNA phage display library, representing the antigenic repertoire from axSpA hip synovium, was constructed and screened for reactivity with $\lg A$ antibodies in plasma of early axSpA patients $(n=10)$. Using enzyme-linked immunosorbent assays (ELISA), antibody reactivity against 173 identified targets was initially determined in pooled plasma of early axSpA patients $(n=60)$ and healthy controls $(\mathrm{HC}, n=30)$, collected at Hasselt University. Antigenic targets that showed increased IgA reactivity in axSpA plasma pools were further validated in individual plasma samples of early axSpA patients $(n=79)$ and $\mathrm{HC}(n=101)$.

Results: We identified 10 novel Hasselt University (UH) axSpA peptide targets with increased $\lg A$ antibody reactivity in pooled axSpA plasma. At present, validation of $8 \mathrm{UH}$-axSpA-IgA peptide targets in individual plasma samples revealed antibody reactivity against at least one of these targets in $32 \%$ of early axSpA patients $(25 / 79)$ compared to $26 \%$ in $\mathrm{HC}(31 / 101, p=0.4082)$. By combining the $3 \mathrm{UH}-a x S p A-I g A$ peptides with the highest positive likelihood ratio (LR+) into a panel, an increased overall specificity of $90 \%$ (10/101) could be achieved, with an associated sensitivity of $24 \%(19 / 79, p=0.0138)$ resulting in a LR+ of 2.4 Antibody reactivity testing of the remaining $2 \mathrm{UH}$-axSpA-IgA peptide targets is currently ongoing.

Conclusion: The increased reactivity of IgA (auto)antibodies against several novel antigenic peptide targets underscores the role of the humoral immune response in axSpA, and might indicate a potential link with mucosal inflammation. IgA antibody reactivity against these novel peptide targets will be further validated in independent cohorts of early axSpA patients as well as in patients with chronic low back pain.

Disclosure of Interests: Patrick Vandormael: None declared, Dana Quaden None declared, Pieter Ruytinx: None declared, Joyce Janssens: None declared Johan Vanhoof: None declared, Piet Geusens Grant/research support from: Pfizer, Abbott/Abbvie, Janssen, Celgene, Lilly, Amgen, MSD, UCB, Will, Roche BMS, Novartis, Sanofi, Consultant of: Pfizer, Abbott/Abbvie, Janssen, Celgene, Lilly, Amgen, MSD, UCB, Will, Roche, BMS, Novartis, Sanofi, Veerle Somers Grant/research support from: Research grant from Pfizer and BMS DOI: 10.1136/annrheumdis-2020-eular.4289

\section{AB1258 \\ THE VALUE OF THE SQUEEZE TEST FOR DETECTION OF SUBCLINICAL SYNOVITIS IN PATIENTS WITH ARTHRALGIA SUSPICIOUS FOR PROGRESSION TO RA}

F. Wouters ${ }^{1}$, E. Niemantsverdriet ${ }^{1}$, A. Van der Helm - van Mil ${ }^{1,2} .{ }^{1}$ Leiden University Medical Centre, Department of Rheumatology, Leiden, Netherlands; ${ }^{2}$ Erasmus Medical Centre, Department of Rheumatology, Rotterdam, Netherlands

Background: The squeeze test (or compression test) is often used to quickly screen for arthritis in metacarpophalangeal (MCP)- and metatarsophalangea (MTP)-joints. A positive test is traditionally assumed to indicate presence of synovitis. Previous studies in early arthritis indeed showed that a positive squeeze test was associated with presence of swollen MCP- and MTP-joints, as well as with local MRI-detected inflammation. The sensitivity of the test, with MRI-detected synovitis as reference, was $31-33 \%$. The field is moving towards identifying patients at risk for rheumatoid arthritis (RA) in the phase of arthralgia. However, it is unclear if the squeeze test in the phase of clinically suspect arthralgia (CSA) is associated with subclinical inflammation, which can be detected with MRI

Objectives: We aimed to assess if a positive squeeze test in patients with CSA is associated with MRI-detected subclinical inflammation, especially with 
subclinical synovitis and tenosynovitis (the latter is recently identified as a strong predictor for RA-development).

Methods: 315 patients with recent-onset $(<1$ year) arthralgia of small joints and a clinical suspicion for progression to RA were consecutively included in our CSA-cohort. At baseline the squeeze test (compression across the knuckles of MCP- and MTP-joints with the force of a firm handshake) and unilateral contrast-enhanced 1.5T MRI of MCP(2-5)- and MTP(1-5)-joints was performed and scored according to RAMRIS. MRI-scores were dichotomized with data from age-matched symptom-free controls as reference. Follow-up ended when patients developed clinically apparent inflammatory arthritis (IA), or else after 2 years. Associations of the squeeze test and MRI-data were studied with generalized estimating equations, associations with IA-development with cox regression. Results: $51 \%$ of CSA-patients had a positive squeeze test in MCP- or MTPjoints. In univariable analyses a positive test was associated with MRI-detected subclinical synovitis (OR $2.10(95 \% \mathrm{Cl} 1.30-3.40))$ and tenosynovitis (OR 1.68 (1.05-2.68)). In multivariable analyses including both inflammatory features only synovitis remained significant (OR 1.90 (1.16-3.13)). Thus, a positive squeeze test is a measure of subclinical synovitis, with a sensitivity of $44 \%(95 \% \mathrm{Cl} 33-55)$ and specificity of $72 \%(68-76)$.

A positive squeeze test in CSA was not associated with IA-development in cox regression adjusted for age, gender, CRP and ACPA-status (HR 1.57 (0.77-3.19). This was consistent with the finding that subclinical synovitis was not associated with IA-development in multivariable analysis adjusted for age, gender, CRP, ACPA-status and tenosynovitis (HR 1.40 (0.59-3.31), whilst tenosynovitis was associated (HR 4.94 (2.03-12.06).

Conclusion: The squeeze test is a simple test that, when positive in CSA, doubles the probability of presence of subclinical synovitis.

Disclosure of Interests: None declared

DOI: 10.1136/annrheumdis-2020-eular.1730

\section{Rehabilitation}

\begin{tabular}{|l|l}
\hline AB1259 & THE IMPACT OF DIFFERENT EXERCISE MODES AND \\
INTENSITIES ON PAIN AND ENJOYMENT IN PEOPLE \\
WITH EARLY RHEUMATOID ARTHRITIS
\end{tabular}

C. Balchin ${ }^{1}$, A. L. $\operatorname{Tan}^{2,3}$, L. A. Bissell ${ }^{2,3}$, C. Reilly ${ }^{1}$, J. Mckenna ${ }^{1}$, O. Wilson ${ }^{1}$ A. Stavropoulos-Kalinoglou'. ' 'Leeds Beckett University, Leeds, United Kingdom; ${ }^{2}$ Leeds Institute of Rheumatic and Musculoskeletal Medicine, University of Leeds, Leeds, United Kingdom; ${ }^{3}$ NIHR Leeds Biomedical Research Centre, Leeds Teaching Hospitals NHS Trust, Leeds, United Kingdom

Background: The benefits of exercise for people with rheumatoid arthritis (RA) are now widely recognised [1]. However, exercise participation among people with RA remains low. A key reason for that could be the commonly held belief that exercise, may exacerbate disease activity while acutely increasing levels of joint pain. The association of acute exercise with pain has not been established in RA and especially in people with a recent diagnosis.

Objectives: This study investigated the impact of acute aerobic-and resistance-type exercise on perceptions of pain in people with early RA.

Methods: Following local NHS ethical approval, ten people with RA volunteered for the study (Age $=46 \pm 13$ years; $B M I=29.4 \pm 8.6 \mathrm{~kg} / \mathrm{m}^{2}$, RA diagnosis= $13 \pm 9$ months, mean $\pm S D$ ). Inclusion criteria were RA diagnosis (2010 EULAR criteria) within the last two years and not engaging in regular physical activity (i.e. no participation in structured exercise $>2$ times per week). They were assessed for maximal aerobic capacity and maximal strength at chest press, leg press and wide-grip lateral pulldown to determine intensities for exercise conditions. Thereafter they completed one no-exercise control trial (CON) and four exercise trials: 30 minutes of sub-maximal cycling at a workload equivalent to $65 \% \mathrm{VO}_{2} \max$ (CYCLE); high intensity interval exercise consisting of $10 \times 1$ minutes cycling intervals at a workload equivalent to $95 \% \mathrm{VO}_{2} \max (\mathrm{HIIE})$; resistance exercise consisting of three sets of 12-15 repetitions at 70\%1RM (RES-70); resistance exercise consisting of three sets of repetitions to failure at 30\%1RM (RES-30). All trials were randomised and separated by a washout period of 3-7 days. Participants completed a a visual analogue scale (VAS) for pain at baseline then 2-and 24-hours post exercise; they also completed a questionnaire related to exercise enjoyment 2-and 24-hours post exercise.

Results: Currently four RA participants have completed the study and all participants completed the prescribed exercises in full. Perceived pain was low at 2 hours $(0.7 \pm 0.4)$ and 24 hours post-exercise $(1.2 \pm 0.8)$ for all exercise conditions (see table 1). Importantly, a difference in heart rate between the aerobic conditions (heart rate during HIIE was $16 \%$ higher than during CYCLE), and a difference in workload between the resistance conditions (RES-30 was $117 \%$ higher than RES-70) did not result in a difference in pain perception. One participant reported increased pain at 24 hours $(7 \mathrm{~cm}$ vs $1 \mathrm{~cm}$ at 2 hours) post RES-30, but claimed that this was purely muscular and not joint pain. Interestingly, all participants enjoyed the exercises with comparable high results across the exercise conditions (see table 1 )

Table 1 Pain and Enjoyment Descriptives

\begin{tabular}{lccccc}
\hline Trial & $\begin{array}{c}\text { Baseline VAS } \\
\text { pain } \mathbf{( c m )}\end{array}$ & $\begin{array}{c}\text { 2-hour VAS } \\
\text { pain } \mathbf{( c m )}\end{array}$ & $\begin{array}{c}\text { 24-hour VAS } \\
\text { pain } \mathbf{( c m )}\end{array}$ & $\begin{array}{c}\text { 2-hour exercise } \\
\text { enjoyment (1-119) }\end{array}$ & $\begin{array}{c}\text { 24-hour exer- } \\
\text { cise enjoyment } \\
\text { (1-119) }\end{array}$ \\
\hline CON & $0.1 \pm 0.3$ & $0.1 \pm 0.3$ & $0.3 \pm 0.3$ & $63.8 \pm 13.0$ & $63.8 \pm 13.0$ \\
CYCLE & $0.1 \pm 0.3$ & $0.5 \pm 0.4$ & $0.9 \pm 1.2$ & $86.8 \pm 11.0$ & $88.0 \pm 8.8$ \\
HIIE & $0.1 \pm 0.3$ & $1.3 \pm 1.9$ & $1.1 \pm 1.7$ & $85.0 \pm 27.8$ & $88.3 \pm 19.1$ \\
RES-70 & $0.1 \pm 0.3$ & $0.4 \pm 0.4$ & $0.5 \pm 0.4$ & $91.3 \pm 13.0$ & $88.3 \pm 6.6$ \\
RES-30 & $0.1 \pm 0.3$ & $0.4 \pm 0.5$ & $2.4 \pm 3.1$ & $88.5 \pm 17.1$ & $85.0 \pm 13.1$ \\
\hline
\end{tabular}

(mean \pm SD)

Conclusion: This study identified minimal exercise effect on perceived pain at 2 hours-and 24 hours-post exercise among participants with early RA. This suggests that exercise did not exacerbate pain and importantly, high intensities and high loads did not cause additional pain. Nevertheless, further larger studies are required to examine the role of acute exercise on disease activity, e.g. inflammation, and the association with perceived pain in people with early RA.

References:

[1] Combe B, et al. 2016 update of the EULAR recommendations for the management of early arthritis. Annals of the Rheumatic Diseases 2016; 76: 948-959.

Disclosure of Interests: None declared

DOI: 10.1136/annrheumdis-2020-eular.3519

$\mathrm{AB} 1260$

ARE THERMAL CURE AND REHABILITATION EFFECTIVE FOR RELIEVING LOW BACK PAIN? RESULTS OF A RANDOMIZED CONTROLLED TRIAL

A. Fazaa ${ }^{1}$, N. Belguith ${ }^{2}$, A. Abdennebi ${ }^{3}$, J. Mbarek $^{4}$, S. Miladi ${ }^{1}$, M. Sellami ${ }^{1}$, K. Ouenniche ${ }^{1}$, S. Kassab ${ }^{1}$, S. Chekili ${ }^{1}$, L. Souabni ${ }^{1}$, A. Ben Hamida ${ }^{5}$,

L. Zakraoui ${ }^{1}$, K. Ben Abdelghani ${ }^{1}$, A. Laatar ${ }^{1} .{ }^{1}$ Hôpital Mongi Slim, Rhumatology, La Marsa, Tunisia; ${ }^{2}$ institut kassab d'orthopédie, médecine physique rééducation et réadaptation fonctionnelle, Mannouba, Tunisia; ${ }^{3}$ station thermale Djbal ElOuest, Zaghouan, Tunisia; ${ }^{4}$ centre de rééducation Jbal El Ouest, Zaghouan, Tunisia; ${ }^{5}$ faculté de medecine de Tunis, épidemilogie, Tunis, Tunisia

Background: Low back pain (LBP) is a major health problem around the world. It affects almost $80 \%$ of the population. Patient with LBP suffer from a heavy pain which is associated to long time incapacity. Different methods of treatment are applied in the objective of reducing pain and thus improving functional capacities of patients.

Objectives: Our study aimed to compare the benefits, with regard to LBP symptoms, of a thermal cure and a rehabilitation treatment.

Methods: It is a randomized therapeutic trial including patients with LBP, randomly divided into two groups: thermal cure and physical rehabilitation. Both of them were conducted in the same spa center of Djbal El Ouest. Outcome measures were visual analogic scale of pain (VAS), Oswestry Disability Index (ODI), Short Form-36 (SF36) questionnaire and schober test. Evaluation was carried out at day 18, 3 months, 6 months and 12 months following treatment.

Results: Seventy-four patients were included, divided into 2 groups: thermal group $(n=37)$ and dry rehabilitation group $(n=37)$. Seventy patients performed the full treatment.

In the group of patients treated with thermal cure treatment $(n=37)$, a significant improvement of VAS of pain, ODI and SF 36 was noted in day 18,3 months, 6 months and 12 months (Table 1).

Table 1. Tendencies of the clinical indexes after treatment by thermal cure

\begin{tabular}{|c|c|c|c|c|c|}
\hline & $\begin{array}{c}\text { D0 } \\
(n=37)\end{array}$ & $\begin{array}{c}D 18 \\
(n=37)\end{array}$ & $\begin{array}{l}\text { 3months } \\
(n=35)\end{array}$ & $\begin{array}{c}\text { 6months } \\
(n=32)\end{array}$ & $\begin{array}{c}\text { 12months } \\
(n=36)\end{array}$ \\
\hline $\begin{array}{l}\text { VAS } \pm S D \\
P\end{array}$ & $68,2 \pm 16,23$ & $\begin{array}{c}35,8 \pm 26,5 \\
0,000\end{array}$ & $\begin{array}{c}55 \pm 19 \\
0,000\end{array}$ & $\begin{array}{c}60,2 \pm 18,1 \\
0,008\end{array}$ & $\begin{array}{c}56,1 \pm 19 \\
0,002\end{array}$ \\
\hline ODI \pm SD & $38,3 \pm 14,1$ & $29 \pm 17,5$ & $32 \pm 14,1$ & $30,2 \pm 14,1$ & $128,5 \pm 13,6$ \\
\hline $\mathbf{P}$ & & 0,03 & 0,03 & 0,07 & 0,000 \\
\hline SF 36 physical mean score $\pm S$ & D34,4 $\pm 14,3$ & $64,2 \pm 18$ & $45,9 \pm 19$ & $50 \pm 21,8$ & $47,9 \pm 18,5$ \\
\hline $\mathbf{P}$ & & 0,000 & 0,000 & 0,000 & 0,001 \\
\hline SF36 mental mean score \pm SD & $38,9 \pm 16,3$ & $71 \pm 21,6$ & $55,1 \pm 20,4$ & $456,4 \pm 19,9$ & $952,2 \pm 20,8$ \\
\hline & & 0,000 & 0,000 & 0,000 & 0,000 \\
\hline $\begin{array}{l}\text { Scober test } \pm \text { SD } \\
\text { P }\end{array}$ & $3,1 \pm 1,3$ & $\begin{array}{c}3,5 \pm 1,3 \\
0,037\end{array}$ & $\begin{array}{c}2,8 \pm 1 \\
0,322\end{array}$ & $\begin{array}{l}3 \pm 1,1 \\
0,812\end{array}$ & $\begin{array}{c}3,2 \pm 1,5 \\
0,657\end{array}$ \\
\hline
\end{tabular}

VAS: visual analog scale; ODI: Oswestry Disability Index; SF36: short form 36 